\title{
What We Regret Most ... and Why
}

\author{
Neal J. Roese \\ Amy Summerville \\ University of Illinois
}

Which domains in life produce the greatest potential for regret, and what features of those life domains explain why? Using archival and laboratory evidence, the authors show that greater perceived opportunity within life domains evokes more intense regret. This pattern is consistent with previous publications demonstrating greater regret stemming from high rather than low opportunity or choice. A meta-analysis of 11 regret ranking studies revealed that the top six biggest regrets in life center on (in descending order) education, career, romance, parenting, the self, and leisure. Study Set 2 provided new laboratory evidence that directly linked the regret ranking to perceived opportunity. Study Set 3 ruled out an alternative interpretation involving framing effects. Overall, these findings show that people's biggest regrets are a reflection of where in life they see their largest opportunities; that is, where they see tangible prospects for change, growth, and renewal.

Keywords: regret; counterfactual; cognitive dissonance; decision making; emotion

A life lived is a life replete with choices. Some go well, some go wrong, and those gone wrong spell regret. You could have done it differently ... should have said something else ... and you might have come out ahead. Recent research on regret has pinpointed numerous cognitive consequences, including effects on blame, expectancies, superstition, suspicion, and ongoing behavior (Connolly \& Zeelenberg, 2002; Roese, 1997, 2005). When looking across life as a whole, what do people regret most? Which aspects of life, career versus romance, school versus children, spirituality versus money, come most vividly to mind, perhaps to haunt the individual for extended periods of time? And why?

This article addresses these questions in three ways. First, several previous studies have reported rankings of people's biggest regrets in life, but until now there has not been an integrative summary of those findings. Accordingly, we present a meta-analysis of these findings using a 12-category framework of life domains; this framework is also used in our laboratory studies. Second, we account for why this ranking occurs by pointing to an opportunity principle, apparent in several lines of recent research that have not previously been summarized together. By opportunity, we mean an open rather than closed door to further action in the service of correction, advancement, and betterment, defined in terms of the individual's perception of situational features or personal talents that enable such pursuit. Third, we offer new laboratory evidence that builds a bridge between these two previously separate bodies of work.

\section{Regrets Big and Small}

Regret has been defined as a negative emotion predicated on an upward, self-focused, counterfactual inference (Gilovich \& Medvec, 1995; Zeelenberg, 1999). Regret feels bad because it implies a fault in personal action: You should have done it differently, hence selfblame is a component of regret (Connolly \& Zeelenberg, 2002). The vast majority of research on regret has focused on structural properties, such as the distinction between regrets of inaction versus action, and on the effects of anticipated and felt regret on decision making. A handful of publications have taken a different approach, that of content analyzing regrets to give an indication of where in life regrets persist.

In the meta-analytic summary that follows, we see that Americans' six biggest regrets fall into the following life domains (in descending order of frequency): education, career, romance, parenting, self-improvement, and lei-

Authors' Note: Preparation of this article was supported by National Institute of Mental Health Grant 5R01-MH055578-07. We thank Justin Kruger and Jim Olson for comments, Nathan Kuncel for meta-analytic advice, and Joseph Dewlow, Jeff Kuban, Michael Nickolau, Karen Talbert, and Patrick Wadlington for assistance in data collection. Address correspondence to Neal Roese, Department of Psychology, University of Illinois, Champaign, IL 61820; e-mail: roese@uiuc.edu.

PSPB, Vol. 31 No. 9, September 2005 1273-1285 DOI: $10.1177 / 0146167205274693$

(C) 2005 by the Society for Personality and Social Psychology, Inc. 


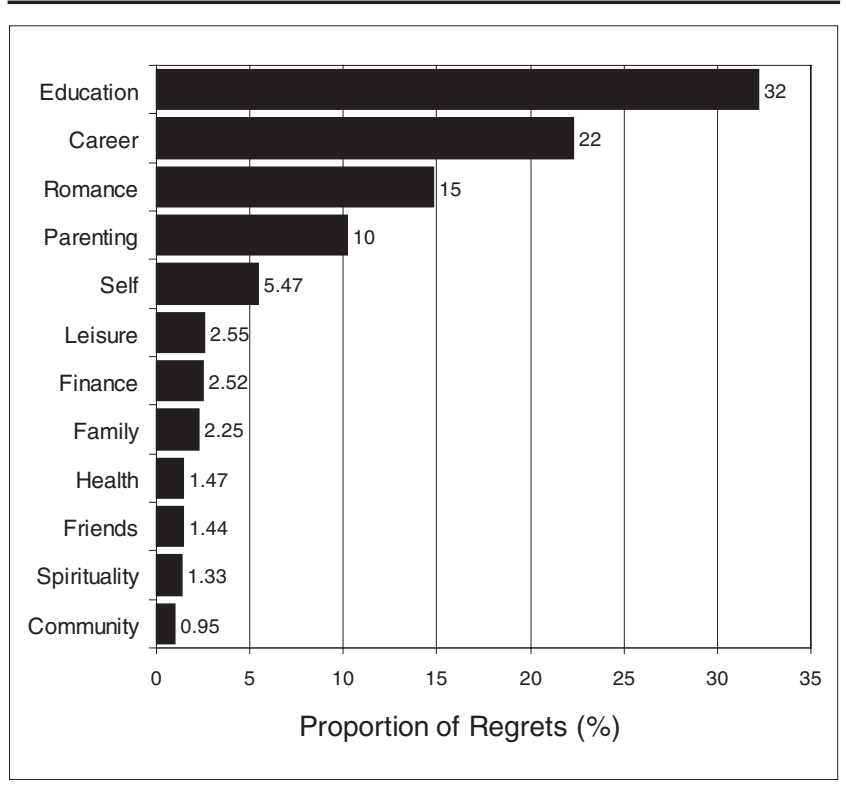

Figure 1 What we regret most (meta-analytic summary).

sure (see Figure 1). But why should this particular ranking occur? Indeed, that education appears as the number one regret of Americans is a remarkably consistent finding across these studies (e.g., should have stayed in school, should have studied harder, should have gotten another degree). Why might this be so? We argue that one answer to this question may be derived from a variety of recent findings that converge on the principle that opportunity breeds regret. An impressive range of findings support this idea, and a major goal of this article is to apply this principle to an understanding of what we regret most.

\section{The Opportunity Principle}

Opportunity breeds regret. Feelings of dissatisfaction and disappointment are strongest where the chances for corrective reaction are clearest. There are two reasons for this counterintuitive finding. First, where opportunity is denied, or where problematic circumstances are inevitable, processes of cognitive dissonance, rationalization, and reconstrual are engaged that either terminate or substantially mitigate the experience of regret. Accordingly, regret persists in precisely those situations in which opportunity for positive action remains high. This perspective offers a novel explanation for why education is the number one regret of Americans of diverse age, socioeconomic status, and life circumstance: In contemporary society, education is open to continual modification throughout life. With the rise of community colleges and student aid programs in recent decades, education of some sort is accessible to nearly all socioeconomic groups. You can always go back to school.
A second and more basic reason underlying this opportunity principle is that regret spurs further corrective action. Regret pushes people toward revised decision making and corrective action that often bring improvement in life circumstances (Zeelenberg, 1999). For example, Zeelenberg and Pieters (1999) measured regret in response to negative experiences with service providers (e.g., taxis, restaurants) and showed that regret predicted subsequent switching to new service providers (see also Zeelenberg, Inman, \& Pieters, 2001). Moreover, regret is predicated on an upward counterfactual inference, and both laboratory and field research indicate that upward counterfactual thinking elicits subsequent performance improvement by way of its inferential implications for behavioral modification (Morris \& Moore, 2000; Nasco \& Marsh, 1999; Roese, 1994). These findings reveal that regret often initiates corrective action, but clearly, individuals are more likely to undertake corrective action when they believe it to be both possible and effective.

At least five separate lines of recent research converge on this opportunity principle. Perhaps the clearest experimental demonstration was conducted by Markman, Gavanski, Sherman, and McMullen (1993), who manipulated the outcomes experienced by participants playing a computer-presented blackjack game. Negative outcomes evoked more upward counterfactual thoughts (and hence more regret) than positive outcomes, but this effect was qualified by whether participants had the opportunity to play another round. Such opportunity to "fix the situation next time" increased the tendency to generate upward counterfactuals, and these authors interpreted their findings in terms of the usefulness of channeling insights into how the past might have been improved into subsequent opportunities. By the same token, outcomes perceived to be more controllable also evoke more upward counterfactual thoughts than less controllable outcomes (Roese \& Olson, 1995).

Second, a recent experimental demonstration focused on whether decisions may be subsequently revised, as when consumers return purchased goods for a refund (Gilbert \& Ebert, 2002). Using the guise of a photography class, participants selected their own photographs to keep, but this decision was reversible for some (i.e., they could change their mind and keep a different photo) and irreversible for others. Irreversible decisions aroused greater dissonance reduction (or to use their terminology, activation of a psychological immune system), thereby elevating decision satisfaction. With reversible decisions however, the recognition of opportunity for further rectification interfered with dissonance reduction, resulting in reduced satisfaction. Although not a study of regret per se, this research suggests that regret persists in those situations that are per- 
ceived to be changeable. Gilbert, Morewedge, Risen, and Wilson (2004) demonstrated further that people ordinarily suppress, distort, and quash many of life's daily regrets, typically without even realizing it. Some smaller subset of regrets-those reflecting changeable circumstances-are the ones that remain to haunt people further.

In a third line of research, Gilovich, Medvec, and Chen (1995) showed that one reason why regrets of inaction persist longer than regrets of action is that cognitive dissonance reduction is more active for the latter than the former. Regrets of inaction ("Should have asked her out," "Should have become a dentist") are more psychologically "open," more imaginatively boundless, meaning that there is always more one could have done and further riches one might have enjoyed ("She'd have been a wonderful partner," "It would have been rewarding work"). This openness to possibility (the essence of opportunity) mitigates dissonance reduction. By contrast, regrets of action are psychologically fixed by their factual status and have only one alternative (not doing it). With the consequences of factual action plain as day, cognitive dissonance is more readily aroused to mitigate the sting of those consequences (Gilovich \& Medvec, 1995). Thus, regrets of inaction last longer than regrets of action in part because they reflect greater perceived opportunity.

The number of options from which to choose was the focus of a fourth line of research by Iyengar and Lepper (2000). Participants given a larger number of product options to examine and select from (e.g., 24 different flavors of jam) were less likely to buy the product and also felt less satisfaction and more frustration than those given few options (e.g., 6 flavors). Study 3 of this article included a measure of regret, and although regret analyses were presented within an aggregate satisfaction measure, it is clear from the direction of the effect that greater perceived opportunity (born of wider choice options) evoked more regret (e.g., "If only I'd tried every last jam, I might have found the perfect flavor"; see also Schwartz, 2000).

A fifth line of research centered on age. As people grow older, their choices become increasingly constrained. A new romance or a new career are open possibilities for the young but somewhat more difficult for the elderly. Wrosch and Heckhausen (2002) discovered that older individuals produce regrets focusing only rarely on personal action. As their own opportunities fade with advancing years, so too do the most painful and selfrecriminating regrets, to be replaced instead by "neutered" regrets that emphasize the actions of other people. In short, this analysis of age effects showed that with diminishing opportunity comes diminished regret.

\section{Current Research}

Based on these previous demonstrations, we suggest that the domains in life that contain people's biggest regrets are those marked by the greatest opportunity for corrective action. The research was designed to bridge these two previously unrelated lines of research on regret rankings versus the opportunity principle. The first study is a meta-analysis of previously published regret rankings. The next two studies are laboratory investigations of the role of opportunity in regret intensity, positioned within the framework of life domains. Finally, three studies are briefly summarized that rule out an alternative interpretation of the opportunity principle centering on framing effects.

\section{STUDY 1: META-ANALYSIS}

Between 1989 and 2003, nine papers were published containing tabulations of life regrets. The first published report, by Kinnier and Metha (1989), required participants to look over their whole life and if they could live it again, to check as many as 3 aspects of their life that they would change from a list 8 life domains. ${ }^{1}$ The sample consisted of adults of varying ages and occupations approached by graduate counseling students as part of a class project. Landman and Manis (1992) used the same measurement strategy in the following three samples: undergraduates, adult women who had contacted the University of Michigan Women's Center, and a collection of adults culled from a motor vehicle licensing database. DeGenova (1992) asked a representative sample of elderly residents of Lafayette, Indiana, what aspects of their lives they would change if they could; respondents gave ratings of desired change for 35 life domains. Gilovich and Medvec's (1994) Study 2 was a survey of people's biggest regrets in life, later content coded by hypothesis-blind judges. Participants ranged from undergraduates to clerical staff to emeritus professors at Cornell University. In a fascinating follow-up from that same Cornell team, Hattiangadi, Medvec, and Gilovich (1995) reanalyzed data from the Terman genius studya multidecade longitudinal study of highly intelligent individuals initiated by Lewis Terman in 1921. The respondents were elderly when they completed the 1986 survey that indicated that even the intellectually gifted suffer the same sorts of regrets in life as the average person. Landman, Vandewater, Stewart, and Malley (1995) also used secondary data collected in 1986, this time consisting of adult female participants of a multidecade longitudinal study of life issues and values. These respondents were about 43 years old at the time of data collection. Lecci, Okun, and Karoly (1994) sampled community college students, and Wrosch and Heckhausen 
(2002) sampled Berliners recruited via newspaper advertisements; both studies asked participants to describe regrets that were later categorized into life domains by hypothesis-blind judges. Jokisaari (2003) asked students in Finland to record three different life regrets, which independent coders later categorized into 11 life domains.

Overall, five data sets used the method of having participants select their biggest regrets from a list provided by the researchers (DeGenova, 1992; Kinnier \& Metha, 1989; Landman \& Manis, 1992, Samples 1 and 2; Landman et al., 1995); the remainder used the strategy of having participants record regrets, with independent coders subsequently assigning them to life domain categories. Also, in three of the data sets (Landman et al., 1995; Lecci et al., 1994; Wrosch \& Heckhausen, 2002), the researchers restricted their measure to regrets of inaction, whereas the remainder were neutral with regard to soliciting both regrets of action and inaction.

\section{Method}

Data sets. We examined nine published journal articles containing a total of 11 data sets (all reported 1 data set, with the exception of Landman \& Manis, 1992, who reported 3). These articles were identified using standard computer literature search (PsycInfo, SSCI) and also by e-mail canvassing of experts on the study of regret. Together, these data sets comprised 3,041 participants who provided, rated, or checked off a total of 4,054 distinct regrets. Overall, women were overrepresented relative to men ( $73 \%$ of all participants; 2,216 women and 819 men). ${ }^{2}$

Some studies required participants to report a single regret, whereas others permitted participants to nominate multiple regrets from various life domains. To combine across these different methodologies, we used the regret as the unit of analysis for each study, computing the proportion of all regrets that fell within each of the life domain categories.

Coding. One challenge of this analysis was that the life domain categories used in these studies differed. Although on the whole there was remarkable agreement of category structure, alignment was not perfect. For example, Landman and Manis (1992) used 4 categories, Lecci et al. (1994) used 11 categories, and DeGenova (1992) used 35 categories (across 11 data sets, mean number of categories $=14.8$ ). To average across the studies, we required a common framework for categorizing life domains. We drew on prior theoretical conceptualizations of the domains of life priorities (e.g., Cummins, 1996; Frisch, Cornell, Villanueva, \& Retzlaff, 1992; Oishi \& Diener, 2001) to derive a 12-category framework of life domains, intended both to be representative of this prior theoretical work and also to map maximally onto the majority of the ad hoc categorical schemes used within the reviewed studies. Our 12-category framework is summarized in Table 1.

We then matched each category of tabulated regret from each study to 1 or more of these 12 categories. Where individual studies drew finer categorical distinctions, we simply summed the frequencies according to the 12-category framework. Where studies drew broader distinctions that overlapped 2 or more of the categories in the 12-category scheme, we distributed the frequency evenly across those categories. For example, in Hattiangadi et al. (1995), 1 regret category was "should have emphasized social relationships," which received a count of 13 regrets overall (p. 180). This could be interpreted as fitting the categories of family, friends, or romance; it therefore was assigned a count of 4.33 to each of these categories.

Results

With total number of regrets tabulated for each category for each data set, we then computed proportions of total regrets for each category, weighted these by sample size, then computed the weighted within-category average proportion. These means for each category within each study appear in Table 2. The weighted average proportion of all sample regrets then constituted the basis of the ranking of what people regret most, depicted in Figure 1 and with further detail provided in the first column of Table 3.

Education is the number one life regret, accounting for $32.2 \%$ of all reported regrets $(S D=1.89)$. This is a strikingly consistent finding, confirmed by a wide margin in all but two data sets (those exceptions being Landman et al., 1995, and Data Set 3 of Landman \& Manis, 1992). Career ranked number two $(22.3 \%, S D=$ $3.28)$, romance ranked number three $(14.8 \%, S D=$ 2.34), parenting ranked number four $(10.2 \%, S D=$ $2.17)$, self ranked five $(5.47 \%, S D=2.52)$, and leisure ranked six $(2.55 \%, S D=2.34)$. These top six biggest regrets accounted for $86.4 \%$ of all regrets mentioned across all participants. The mean proportions corresponding to the top five regrets each differed significantly from one another, as tested using one-tailed post hoc comparisons between adjacently ranked means $(p s=$ $.003, .02, .04, .04$, in descending order of rank). The difference between the fifth and sixth ranked regrets (self and leisure) did not differ significantly, $p=.14$.

The remaining six regrets were so low in frequency as to be effectively inconsequential; they were finance $(2.46 \%, S D=1.29)$, family $(2.23 \%, S D=1.19)$, health $(1.47 \%, S D=0.84)$, friends $(1.45 \%, S D=0.75)$, spirituality $(1.26 \%, S D=1.10)$, and community $(0.95 \%, S D=$ $0.68)$. Not surprisingly, none of these mean proportions differed reliably from one another, $p s>.35$. 
TABLE 1: Twelve Life Domains

1. Career: jobs, employment, earning a living (e.g., "If only I were a dentist")

2. Community: volunteer work, political activism (e.g., "I should have volunteered more")

3. Education: school, studying, getting good grades (e.g., "If only I had studied harder in college")

4. Parenting: interactions with offspring (e.g., "If only I'd spent more time with my kids")

5. Family: interactions with parents and siblings (e.g., "I wish I'd called my mom more often")

6. Finance: decisions about money (e.g., "I wish I'd never invested in Enron")

7. Friends: interactions with close others (e.g., "I shouldn't have told Susan that she'd gained weight")

8. Health: exercise, diet, avoiding or treating illness (e.g., "If only I could stick to my diet")

9. Leisure: sports, recreation, hobbies (e.g., "I should have visited Europe when I had the chance")

10. Romance: love, sex, dating, marriage (e.g., "I wish I'd married Jake instead of Edward")

11. Spirituality: religion, philosophy, the meaning of life (e.g., "I wish I'd found religion sooner")

12. Self: improving oneself in terms of abilities, attitudes, behaviors (e.g., "If only I had more self-control")

\section{STUDY 2A: COLLEGE STUDENTS' REGRET RANKING}

Study 2 a was a laboratory survey conducted among college students, the main goal of which was to generate a new ranking of regrets that would serve as the benchmark against which the opportunity manipulation of Study 2b, conducted among a similar sample of students at the same university, could be gauged. That is, in Study $2 \mathrm{~b}$, participants were directed to focus on high and low opportunity life domains, then to rate the intensity of regrets falling into these life domains. We could then observe directly whether those life domains deemed by participants to be high in opportunity (Study 2b) were generally the same ones identified as containing life's biggest regrets (Study 2a).

We noted previously that some of the meta-analyzed studies required participants first to record a regret, then only later was this regret categorized into a life domain. Other studies presented participants with a list of life domains and then were required to select domains containing their biggest regrets. The latter procedure may have demand characteristics in that participants might attempt to project a favorable impression of themselves by expressing remorse over their lack of spirituality, for example, but may perhaps not mention such a regret had this category not been provided to them explicitly. Accordingly, we used the former procedure, that of inviting participants to share a regret with no mention of particular life domains. Later, participants themselves categorized their regret into one of the 12 life domains.

\section{Method}

Participants were 34 (19 women, 14 men) undergraduate students who completed the study in exchange for credit in an introductory social psychology course at the University of Illinois.

Participants were asked to record a single, vivid regret. To bypass participants' lay (and possibly idiosyncratic) definitions, the word regret was not used in the instructions. Rather, the following paragraph-length description explained the regret information that we sought:

People often see how the past might have been better. You might have acted differently, said something different, and subsequent events might then have unfolded in a different way. Have you ever had one of these thoughts about what might have been that was especially vivid, compelling, or obvious to you? Something you couldn't help but think about repeatedly?

Participants were given eight lines on which to record their vivid regret. At the bottom of the sheet of paper, they were asked to estimate how long ago (in months) the regret-evoking event occurred. On a separate sheet of paper, participants were than asked to categorize their regret into one of the 12 life domains (summarized in Table 1). The domains were presented beside boxes; participants were to check the box beside the selected domain.

\section{Results}

All participants recorded one regret. The duration of the regret (mean elapsed time since initiating incident) was nearly 2 years ( $M=22$ months) but was highly variable $(S D=30.5$, range $=.03$ to 120 months $)$.

The ranking of regrets by frequency of life domain was (1) romance, (2) friends, (3) education, (4) leisure, (5) self, (6) career, (7) family, (8) health, (9) spirituality, (10) community, (11) finance, and (12) parenting. This ranking with frequencies appears in the second column of Table 3. This ranking differs from the meta-analytic result of Study 1 in several nonsurprising ways. Most young adults for example have yet to confront challenges regarding career and parenting, hence these kinds of regrets are rare among college students. Also different from Study 1, regrets of romance ranked highest among the college sample. Given that most college students have yet to settle into committed, long-term relationships, romance for these participants is a domain marked by instability and large opportunity for change. This may be further, albeit indirect, evidence that opportunity breeds regret. Despite these minor dif- 


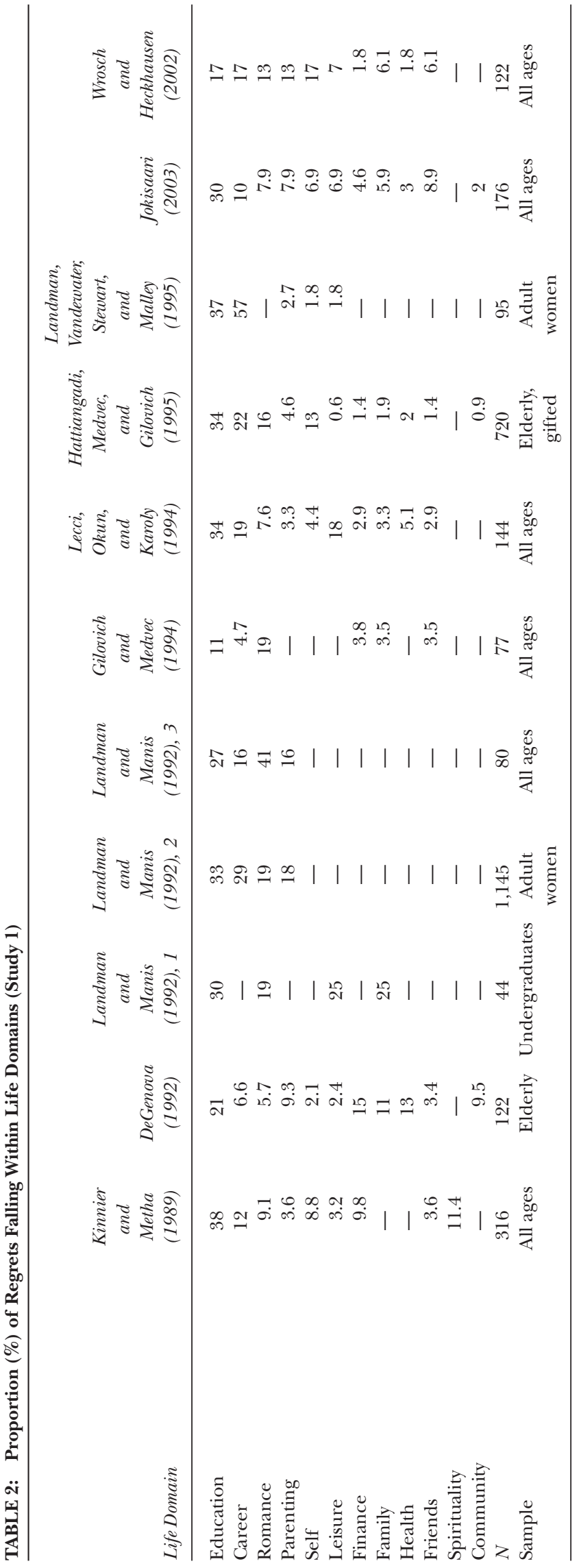


TABLE 3: Rankings of Life Regrets Within Life Domains (Studies 1 and 2a)

\begin{tabular}{|c|c|c|c|c|c|}
\hline \multicolumn{3}{|c|}{ Study 1 (Meta-Analysis) } & \multicolumn{3}{|c|}{ Study $2 a$ (College Student Sample) } \\
\hline Rank & Domain & $\begin{array}{c}\text { Proportion } \\
(\%)\end{array}$ & Rank & Domain & $\begin{array}{c}\text { Frequency } \\
(\%)\end{array}$ \\
\hline 1 & Education & 32.2 & 1 & Romance & 26.7 \\
\hline 2 & Career & 22.3 & 2 & Friends & 20.3 \\
\hline 3 & Romance & 14.8 & 3 & Education & 16.7 \\
\hline 4 & Parenting & 10.2 & 4 & Leisure & 10 \\
\hline 5 & Self & 5.5 & 5 & Self & 10 \\
\hline 6 & Leisure & 2.5 & 6 & Career & 6.7 \\
\hline 7 & Finance & 2.5 & 7 & Family & 3.3 \\
\hline 8 & Family & 2.3 & 8 & Health & 3.3 \\
\hline 9 & Health & 1.5 & 9 & Spirituality & 3.3 \\
\hline 10 & Friends & 1.5 & 10 & Community & 0 \\
\hline 11 & Spirituality & 1.3 & 11 & Finance & 0 \\
\hline 12 & Community & 0.95 & 12 & Parenting & 0 \\
\hline
\end{tabular}

NOTE: The ranking for Study 1 is based on the proportion of all regrets mentioned that centered on a particular life domain (codings sometimes include more than one regret per participant). The ranking for Study 2a is based on the frequency with which the sole regret cited by each participant centered on a particular life domain.

ferences, more striking is the overall similarity in regret ranking between the meta-analysis of Study 1 and the college sample of Study 2a: 5 of the 6 top regrets were the same (for college students, regrets centering on friendships made it into the top 6 , replacing parenting regrets that were in the top 6 of the meta-analysis ranking).

\section{STUDY 2B: EFFECT OF PERCEIVED}

\section{OPPORTUNITY ON REGRET INTENSITY}

Study $2 \mathrm{~b}$ was designed to test the role of opportunity by directing participants' focus of attention onto life domains of high versus low opportunity. We then measured the intensity of regrets associated with those life domains. According to our theoretical perspective, high opportunity life domains should bring to mind higher intensity regrets than life domains characterized by low opportunity. Also, we expected that those life domains nominated as high (vs. low) in opportunity would more closely match those life domains that participants identified in Study 2a as containing their biggest regrets. Such a demonstration would more directly connect perceived opportunity to the findings obtained in the regretranking paradigm.

\section{Method}

Participants were 121 (70 women, 49 men, 2 unspecified) students who completed the study in exchange for credit in an introductory social psychology course at the University of Illinois.

Participants were given a list of the same 12 life domains used in the previous studies and asked to select one example each marked by high and low opportunity. The instructions in the former condition read,

Where in life do you feel you have the MOST opportunity? That is, where in life do you have the greatest freedom to do what you want or the most effective skills that enable you to modify circumstances for the better?

The instructions for the low opportunity condition read,

Where in life do you heave the LEAST opportunity? That is, where in life are your choices constrained, decided often by other people, or simply tough to put into effect? Where in life do you feel that things are more fixed, unchangeable, and hard to modify according to your own desires?

Opportunity was manipulated on a within-subjects basis and counterbalanced. Half the participants first nominated a high opportunity life domain, completed the ratings listed in relation to that life domain, then nominated a low opportunity life domain, and then completed the same ratings but this time with regard to the low opportunity life domain. The other half of participants completed a questionnaire in which low opportunity preceded high opportunity.

The dependent measures were as follows. Participants completed a manipulation check rating of opportunity: "How easy is it to change or modify this part of your life?" (using a 9-point scale with anchors labeled very hard to change and very easy to change). Participants were then instructed to think of a regret from this domain. The main dependent measure centered on perceived intensity of this regret: "How emotionally intense is this regret?" (using a 9-point scale with anchors labeled extremely weak and extremely intense). Last, mainly for exploratory purposes, participants rated the overall importance of the life domain: "How important is this part of your life?" (using a 9-point scale with anchors labeled not at all important and very important).

Results

Two kinds of results are presented. First, by looking at the effect of high versus low opportunity on regret intensity, we reach direct evidence for our conceptual explanation as to where in life regrets persist. Second, by comparing which life domain people nominate for high versus low opportunity against the ranking established in Study 2a, we can draw a direct bridge from Study 2b's manipulation of perceived opportunity to the more standard life regret ranking procedure of Study 2a.

The rating of opportunity confirmed the success of the manipulation. Participants rated the high opportunity life domains as being both higher in opportunity and easier to change than low opportunity domains: for 
opportunity $(M \mathrm{~s}=6.91$ vs. 3.44$), F(1,118)=314.4, p<$ $.001, d=1.62$; for changeability ( $M \mathrm{~s}=6.04$ vs. 2.72$), F(1$, $118)=256, p<.001, d=2.05$. Our main prediction was confirmed in that high opportunity life domains contained more intense regrets than low opportunity domains $(M \mathrm{~s}=4.68$ vs. 4.16$), F(1,118)=4.72, p=.03, d=$ .21. In addition, those life domains that were high in opportunity were also those deemed to be more personally important $(M \mathrm{~s}=7.28$ vs. 6.04$), F(1,118)=30.1, p<$ $.001, d=.50$. This finding may reflect either the fortuitous circumstance of America's educated class or simple self-enhancement (i.e., illusion of control). Importance and opportunity ratings appeared to be relatively unconfounded: The correlation between opportunity and importance ratings was .18 and .27 in the high and low opportunity conditions, respectively. Moreover, an examination of potential multicolinearity in a regression equation predicting regret intensity from opportunity and importance produced variance inflation factor values of 1.02 and 1.08, far smaller than the conventional threshold value of 10 at which multicolinearity may be suspected (Netter, Kutner, Nachtsheim, \& Wasserman, 1996). In this regression (based on the difference scores between high and low opportunity conditions), opportunity $(\beta=.23, p=.008)$ and importance $(\beta=.34, p<$ $.001)$ were significant yet independent predictors of regret intensity.

We next isolated the 6 most frequently nominated domains for both the high and low opportunity conditions. We selected 6 as opposed to the full 12 because those 6 domains that were least frequently cited were mentioned by only a handful of people, resulting in frequencies of close to zero (see Studies 1 and 2a for similar observations). We next tabulated the number of people citing each of the domains for both high and low opportunity conditions; these rankings appear in Table 4 . The mean frequency for the top 6 domains in each condition was nearly identical for high $(13.7 \%)$ and low opportunity (14.0\%).

The key question however centers on whether those life domains that participants selected as high (vs. low) in opportunity are generally the same as those domains that participants in Study 2a selected as containing their biggest regrets. In other words, does the manipulation of opportunity in the present study explain, at least in part, the selection of life domains in the previous study? If individuals' biggest regrets reside within life domains marked by high opportunity, then the frequencies in Study 2a with which particular life domains were selected as containing big regrets should be more similar to the set of life domains chosen in the present study's high versus low opportunity condition. This was indeed the case. The mean frequency in the high opportunity condition was nearly identical to the frequency derived
TABLE 4: Rankings of High Versus Low Opportunity Life Domains

\begin{tabular}{llll}
\hline & & Study $2 b$ & Study $2 a$ \\
Rank & Life Area & Frequency & Frequency \\
\hline
\end{tabular}

Top six high opportunity

domains

2

3

4

5

6

Top six low opportunity domains

1
2
3
4
5
6

$\begin{array}{lrr}\text { Self } & 28.7 & 10.0 \\ \text { Education } & 14.9 & 16.7 \\ \text { Health } & 12.8 & 3.3 \\ \text { Spirituality } & 10.6 & 3.3 \\ \text { Romance } & 7.4 & 26.7 \\ \text { Friends } & 7.4 & 20 \\ \text { Mean } & 13.7 & 13.3\end{array}$

$\begin{array}{lrc}\text { Career } & 21.0 & 6.7 \\ \text { Family } & 21.0 & 3.3 \\ \text { Finance } & 16.0 & 0 \\ \text { Education } & 9.0 & 16.7 \\ \text { Community } & 9.0 & 0 \\ \text { Spirituality } & 8.0 & 3.3 \\ \text { Mean } & 14.0 & 5.0\end{array}$

NOTE: Study 2b frequencies reflect the percentage of individuals who selected a particular life domain as being high versus low in opportunity. Study 2 a frequencies reflect number of individuals who categorized their vivid regret as falling within that life domain.

from Study 2a ( $13.7 \%$ vs. $13.3 \%)$, binomial $Z=.07, p=$ $.47, h=0.01, \log$ odds ratio $=0.03$. By contrast, the mean frequency in the low opportunity condition much exceeded the frequency derived from Study $2 \mathrm{a}(14.0 \%$ vs. $5.0 \%$ ), binomial $Z=2.41, p=.008, h=0.32$, $\log$ odds ratio $=1.03$. Another way of capturing this effect is using Spearman rank order correlations computed across the full set of 12 domains. This analysis similarly showed a high correspondence between Study 2a and 2b within the high opportunity condition, $r(10)=.65, p=.02$, but no reliable correspondence within the low opportunity condition, $r(10)=-.21, p=.51$. Overall, this pattern indicates that the life domains in which individuals describe their biggest regrets correspond to those domains in which individuals see the greatest opportunity. Moreover, these findings represent a direct connection between the test of opportunity effects in Study $2 b$ and the ranking of Study 2a. Opportunity breeds regret.

\section{STUDY SET 3}

To recap, Study Set 2 was designed to be a conceptual bridge, linking research on regret rankings to laboratory manipulations of perceived opportunity. This bridge raises an important theoretical issue centering on the timing of measurement, specifically, whether regret is assessed immediately after an outcome versus recalled much later.

In Study 2b, we used a retrospective self-report method in which participants recalled long-lasting 
regrets. The opportunity effect revealed by this method could however reflect either or both of the following two distinct mechanisms: outcome-evoked effects or post hoc framing effects. Outcome-evoked effects correspond to the psychological effects (dissonance reduction or preparation for new action) that follow immediately from the outcome. For example, failing an exam evokes immediate regret ("I should have studied harder"), the intensity of which is moderated by immediate perceptions of subsequent opportunity. Post hoc framing effects may come later, as when recalling the regretted failure a year later. At this later point in time, framing the recall of this past outcome as high or low in opportunity may also alter the regret experience: The same outcome framed as high rather than low in opportunity might produce greater regret reports. The findings of Study $2 b$ could be interpreted in terms of either or both mechanisms. Prior laboratory research has very clearly demonstrated an outcome-evoked opportunity effect (Gilbert \& Ebert, 2002; Markman et al., 1993), but no past research has examined whether current reports of past regrets are susceptible to framing effects. We conducted three experiments to find out.

Studies $3 \mathrm{a}$ and $3 \mathrm{~b}$ used the same within-subjects design and procedures, differing only in the focal life domains within which regrets were assessed: "kindness and respect in friendships" and "trust in romantic relationships" in $3 \mathrm{a}$ and "meeting new friends" and "time spent with a romantic partner" in $3 \mathrm{~b}$. These pairs were selected (based on a pretest of 24 subareas within the domains of education, romance, and friendship) so as to be equivalent in the number and strength of regrets, importance, and impact on other areas of life. For each of these life domains, two versions of a persuasive paragraph were prepared that argued that past psychology research indicates that most college students have either high or low opportunity to modify events falling within that particular life domain. Participants (University of Illinois undergraduates, $N_{\mathrm{s}}=48,64$ ) were presented with a paragraph about two life domains, one arguing high and the other low opportunity. After reading each paragraph, participants listed three ways that they had observed high versus low opportunity in that domain of their own lives. A manipulation check consisting of two items assessing perceived opportunity emphasized in the paragraphs confirmed the success of this manipulation in both studies: In Study 3a, higher ratings of perceived opportunity appeared in the high than low opportunity condition $(M \mathrm{~s}=5.15$ vs. 4.55$), F(1,46)=6.48, p=.01, d=$ .37 ; and the same was true in Study $3 \mathrm{~b}(M \mathrm{~s}=5.79$ vs. $4.59), F(1,63)=49.5, p<.001, d=.43$. Participants then rated the extent of their own regrets within each life domain using two ratings (frequency and intensity) that were then combined. Although this framing manipula- tion was clearly successful, it produced no consistent effect on the regret ratings. In Study $3 \mathrm{a}$, framing had no reliable effect on the combined regret index $(M \mathrm{~s}=3.46$ vs. 3.49$), F(1,46)=.02, p=.89, d=.02$. In Study 3b, there was a marginally significant effect in the opposite direction (i.e., greater regret for low rather than high opportunity, $M \mathrm{~s}=2.76$ vs. 3.10$), F(1,63)=3.74, p=.06, d=.24$.

Study $3 \mathrm{c}$ involved a different framing manipulation based on accessibility experiences (e.g., Schwarz, 1998) in which participants were asked to generate either many (eight or six, depending on condition) or few (two) examples of the opportunities they perceived within one of four subareas (kindness and respect in friendships, meeting new friends, time spent with romantic partners, trust in romantic relationships; $N=$ 199). ${ }^{3}$ The rationale was that the act of generating eight examples would be perceived to be more difficult than generating two examples and that this inference of difficulty would result in the further inference of correspondingly meager opportunity in that domain. Indexed by perceived difficulty ratings, this manipulation was effective $(M \mathrm{~s}=4.61$ vs. 4.02 , for high and low opportunity conditions), $F(1,198)=6.34, p=.01, d=.36$. But again, this framing manipulation had no significant effect on the combined regret index ( $M \mathrm{~s}=3.00$ vs. 3.05$)$, $F(1,197)=.07, p=.79, d=.04$.

These three experiments suggest that the opportunity effect does not operate via a framing mechanism at the time of recall of past events (weighted mean $d=-.02$, $N=311$ ). Although it is always difficult to draw strong conclusions from null results, the present findings are informative given that the manipulations were shown to be effective and that repeated independent tests were conducted with substantial statistical power. It seems then that previously published laboratory demonstrations of outcome-evoked opportunity effects constitute the principal mechanism by which opportunity breeds regret.

\section{DISCUSSION}

A small but noteworthy subset of previous research on regret has presented tabulations and rankings of where in life people's biggest regrets lie. These reports have appeared in journals spanning social, personality, developmental, and gender psychology and until now have not been summarized comprehensively. In meta-analyzing these findings we found that overall, Americans regret choices made in the context of education. Career, romance, and parenting were ranked two, three, and four, respectively. Rounding out the top six were regrets centering on the self and on leisure. That education is the number one regret finds agreement with national surveys conducted by Gallup in 1949, 1953, and 1965 (Erskine, 1973). 
Interesting though this ranking may be on its own, the key question is why this ranking appears as opposed to some other. More generally, what factor can account for regret intensity across widely divergent life domains? In the introduction, we summarized five lines of research that together reveal an opportunity principle, which is that greater opportunity breeds regret.

This opportunity principle rests on two mechanisms. First, foreclosed opportunity differentially activates processes of cognitive dissonance reduction (Gilbert \& Ebert, 2002), and second, regret itself spurs corrective action, pushing people to change decision strategies, plans, and behaviors so as to improve their life circumstances (Roese, 1994; Zeelenberg, 1999); such corrective action only makes sense when feasible, that is, when opportunities remain open.

After summarizing these two bodies of work (regret rankings on one hand, opportunity principle demonstrations on the other), we next endeavored to make an empirical connection between the two previously separate literatures, regret rankings versus opportunity effects. To erect this conceptual bridge, we tried to bring a little of each into our laboratory experiments. We first measured regrets among college students (Study 2a), then mapped this new regret ranking onto a manipulation of focus on high versus low opportunity life domains (Study 2b). We discovered that high opportunity directs attention to more intense regrets than low opportunity. We then showed that those life domains that participants identified in Study 2b as being high rather than low in opportunity were precisely those domains that were spontaneously identified in Study 2a as vividly regretful. This research thus demonstrated the link between perceived opportunity and regret intensity while at the same time connecting this relation directly to a content-based ranking of regret.

Accordingly, education is the number one regret at least in part because in contemporary society, new and further education of one sort or another is available to nearly all individuals. From community college to pottery classes, from professional certification to high school equivalency, no matter one's age, talent, or life circumstance, going back to school remains an open opportunity for most Americans. Moreover, education is widely recognized to be a gateway to numerous other valued consequences, from higher income to more challenging career to wider diversity of social contacts. Education is therefore a means to achieving several important ends, and any of these ends gone awry might have been avoided with more education. For reasons such as this, we do not expect the same ranking of regrets to appear in other cultures, although we would expect that perceived opportunity will underlie whatever ranking is uncovered (cf., Gilovich, Wang, Regan, Nishina,
2003). Indeed, striking differences in cultures may be predicted on the basis of social-structural constraints on individual behavior. In contemporary American society, individuals enjoy great freedom of choice when it comes to education and career, but in caste-based societies, such as those in the recent past in India and Great Britain, education and career were constrained at birth. It seems extremely plausible that individuals in caste-based societies experience far fewer life regrets centering on education and career than contemporary Americans. By the same token, contemporary Americans have enormous freedom in dating, marriage, and divorce, yet it was not always this way. Might regrets centering on romance be more common today than they were a century ago, when people married young, divorced rarely, and saw few opportunities for alternative romantic partners?

\section{Limitations and Implications}

The meta-analysis of previous content analyses of life regrets was intriguing, yet a few limitations invite new follow-up research. First, the 11 data sets were samples of convenience (with the well educated overrepresented), precluding confidence in the ranking's generality. The one "representative" sample was representative only of Lafayette, Indiana, a predominantly White, midwestern town. Even so, that education represents the number one life regret of Americans can be fairly confidently concluded given the confirmation of this finding in representative surveys conducted in earlier decades (Erskine, 1973). The exact ranking of the remainder of this list however might be verified with a survey using a sample representative of the nation as a whole.

Second, for several of the studies summarized by meta-analysis, the life domain categories were presented to participants before they rated their regrets; these people then decided whether they had experienced a specific regret corresponding to each category. Such an approach may exaggerate frequencies by cuing recall, missing the more interesting question of what it is that people report when not prompted with specific life domains. It may also heighten demand characteristics in that it may suggest to participants that they cite regrets that may make them look good or that the experimenter wants to hear. Some studies used the somewhat better approach of soliciting salient regrets first and only later categorizing these into life domains (typically done by independent coders). In our Study 2a, we used this latter approach but required participants themselves to categorize their own regrets into life domains, thus to some extent reducing the interpretive ambiguity that might affect independent coders.

In characterizing the regret ranking by pointing to the role of opportunity, it seems clear that opportunity is 


\section{Time}

\begin{tabular}{|l|l|l|}
\hline \multicolumn{1}{|c|}{ Action } & \multicolumn{1}{c|}{ Outcome } & \multicolumn{1}{c|}{ Recall } \\
\hline $\begin{array}{l}\text { Nature of Effect: Perceived free } \\
\text { choice of actions and decisions } \\
\text { is necessary for later regret (or } \\
\text { cognitive dissonance) to } \\
\text { emerge. }\end{array}$ & $\begin{array}{l}\text { Nature of Effect. High perceived } \\
\text { future opportunity magnifies } \\
\text { regret that is evoked by failure } \\
\text { outcome. Low opportunity } \\
\text { mitigates regret by activating } \\
\text { processes of dissonance } \\
\text { reduction. }\end{array}$ & $\begin{array}{l}\text { Nature of Effect. Past outcome } \\
\text { framed as high versus low in } \\
\text { opportunity does not alter } \\
\text { ongoing regret experience (i.e., } \\
\text { no framing effects). }\end{array}$ \\
\hline $\begin{array}{l}\text { Relevant Literature: Cognitive } \\
\text { dissonance theory. }\end{array}$ & $\begin{array}{l}\text { Relevant Literature: Regret and } \\
\text { counterfactual thinking. }\end{array}$ & Relevant Literature: n/a \\
\hline $\begin{array}{l}\text { Key Demonstration: Linder et al. } \\
\text { (1967) }\end{array}$ & $\begin{array}{l}\text { Key Demonstration: Markman et } \\
\text { al. (1993) }\end{array}$ & $\begin{array}{l}\text { Key Demonstration: Study Set } \\
\text { 3, this article. }\end{array}$ \\
\hline
\end{tabular}

Figure 2 A summary of opportunity effects on regret.

but one of several determinants of regret intensity. Past research has described other determinants, such as the interplay between action versus inaction and temporal perspective (regrets of action are more intense in the short term; regrets of inaction are more intense over the long term; Gilovich \& Medvec, 1995; Zeelenberg, van der Pligt, \& Manstead, 1998). Our Study 2b showed that opportunity is related to importance in that the most painful regrets are to be found in those life domains that are most important to people. But our research is the first to support the somewhat counterintuitive claim that people's biggest regrets in life are in part a reflection of where in life they see the most opportunity for improvement.

\section{A Theoretical Synthesis of the Opportunity Principle}

Our analysis of the opportunity principle may be summarized concisely in terms of three distinct stages at which opportunity effects may or may not occur with regard to regret experiences. These three stages are action, outcome, and recall (see Figure 2). At the action stage, the individual engages in goal-directed behaviors prior to a focal outcome, such as studying before an exam. It is at this stage that research from the cognitive dissonance literature may be brought to bear. As this literature itself made clear, regret is an example of cognitive dissonance (Brehm \& Wicklund, 1970; Festinger \& Walster, 1964; Wicklund \& Brehm, 1976). For any subse- quent experience of regret (or dissonance) to occur, the individual must believe that actions have been freely chosen (Linder, Cooper, \& Jones, 1967). If actions have been constrained by outside forces, the individual seizes on these external attributions and hence feels no dissonance, no regret, and no self-blame ("The power failure prevented me from studying"; e.g., Cooper \& Fazio, 1984). The next stage is the outcome stage, at which the goal is either successfully or unsuccessfully achieved. Almost by definition, regret does not occur for successes, but a failure following from freely chosen actions will evoke regret, which embodies thoughts of alternative actions that might have brought about success. It is at this outcome stage that the opportunity principle operates. As shown in laboratory experiments in which an actual experience is accompanied by beliefs in either low or high opportunities to implement new corrective action (e.g., Gilbert \& Ebert, 2002; Markman et al., 1993), high opportunity exacerbates regret, whereas low opportunity initiates processes of dissonance reduction (which mitigate the experience of regret). But importantly, regret (dissonance) is likely to appear at this outcome stage only to the extent that there was a belief in free choice during the action stage. Finally, at the recall stage, an individual might remember a past experience regretfully, and some regrets linger for long periods of time (Gilovich \& Medvec, 1995). At this recall stage, regret intensity might reflect recollections of the opportunity perceived during the outcome stage, but our research 
rules out the possibility that framing of the past as high or low in opportunity during this recall stage itself alters the regret experience. Rather, recall of past regret experiences reflects the opportunity principle as primarily an outcome-evoked process: Consideration of future opportunity in the immediate aftermath of the outcome moderates regret intensity and accordingly whether this regret lingers over longer periods of time.

\section{Coda}

Opportunity breeds regret, and so regret lingers where opportunity existed. Rankings of life regrets, interesting in and of themselves, point to this deeper theoretical principle. Life regrets are a reflection of where in life people see opportunity, that is, where they see the most tangible prospects for change, growth, and renewal.

\section{NOTES}

1. One commonly cited paper did not appear in the meta-analysis (Metha, Kinnier, \& McWhirter, 1989) because it seemed that its data were redundant to those presented in Kinnier and Metha (1989). The only apparent difference is that the former paper reports data for the female participant subset included in the latter paper.

2. Proportion of men and women are estimates, not exact values, as two of the nine studies did not report sex of subject information (an even split was thus assumed). The oversampling of women derives largely from Landman and Manis's (1992) second data set, which included 1,145 women and no men. Sex differences are almost completely absent from the literature of counterfactual thinking and regret, a null finding that extends to the studies reviewed here. Women and men are remarkably similar in the aspects of life that they regret most, hence the oversampling poses little concern regarding the generalizability of this meta-analysis.

3. The number of examples listed (two, six, or eight) was developed from the number of examples generated during pretesting of 55 participants. The modal number of examples generated in each domain was multiplied by .5 to set the number for the few condition and 1.5 to set the number for the many condition, a procedure recommended by N. Schwarz (personal communication, November 5, 2004; see also Schwarz, 1998). These values were rounded to the more extreme whole number so that a value of 2.5 for example was rounded down to 2 for the few condition and a value of 7.5 was rounded up to 8 for the many condition.

\section{REFERENCES}

Brehm, J. W., \& Wicklund, R. A. (1970) . Regret and dissonance reduction as a function of postdecision salience of dissonant information. Journal of Personality and Social Psychology, 14, 1-7.

Connolly, T., \& Zeelenberg, M. (2002). Regret in decision making. Current Directions in Psychological Science, 11, 212-216.

Cooper, J., \& Fazio, R. (1984). A new look at dissonance theory. In L. Berkowitz (Ed.), Advances in experimental social psychology (Vol. 17, pp. 229-266). San Diego, CA: Academic Press.

Cummins, R. A. (1996). The domains of life satisfaction: An attempt to order chaos. Social Indicators Research, 38, 303-328.

DeGenova, M. K. (1992). If you had your life to live over again: What would you do differently? International Journal of Aging and Human Development, 34, 135-143.

Erskine, H. (1973). The polls: Hopes, fears, and regrets. Public Opinion Quarterly, 37, 132-145.

Festinger, L., \& Walster, E. (1964). Post-decision regret and decision reversal. In L. Festinger (Ed.), Conflict, decision, and dissonance (pp. 112-127). Stanford, CA: Stanford University Press.
Frisch, M. B., Cornell, J., Villanueva, M., \& Retzlaff, P. J. (1992). Clinical validation of the Quality of Life Inventory. A measure of life satisfaction for use in treatment planning and outcome assessment. Psychological Assessment, 4, 92-101.

Gilbert, D. T., \& Ebert, J. E. J. (2002). Decisions and revisions: The affective forecasting of changeable outcomes. Journal of Personality and Social Psychology, 82, 503-514.

Gilbert, D. T., Morewedge, C. K., Risen, J. L., \& Wilson, T. D. (2004). Looking forward to looking backward: The misprediction of regret. Psychological Science, 15, 346-350.

Gilovich, T., \& Medvec, V. H. (1994). The temporal pattern to the experience of regret. Journal of Personality and Social Psychology, 67, 357-365.

Gilovich, T., \& Medvec, V. H. (1995). The experience of regret: What, when, and why. Psychological Review, 102, 379-395.

Gilovich, T., Medvec, V. H., \& Chen, S. (1995). Commission, omission, and dissonance reduction: Coping with the "Monty Hall" problem. Personality and Social Psychology Bulletin, 21, 182-190.

Gilovich, T., Wang, R. F., Regan, D., \& Nishina, S. (2003). Regrets of action and inaction across cultures. Journal of Cross-Cultural Psychology, 34, 61-71.

Hattiangadi, N., Medvec, V. H., \& Gilovich, T. (1995). Failing to act: Regrets of Terman's geniuses. International Journal of Human Development, 40, 175-185.

Iyengar, S. S., \& Lepper, M. R. (2000). When choice is demotivating: Can one desire too much of a good thing? Journal of Personality and Social Psychology, 79, 995-1006.

Jokisaari, M. (2003). Regret appraisals, age, and subjective well-being. Journal of Research in Personality, 37, 487-503.

Kinnier, R. T., \& Metha, A. T. (1989). Regrets and priorities at three stages of life. Counseling and Values, 33, 182-193.

Landman, J., \& Manis, J. D. (1992). What might have been: Counterfactual thought concerning personal decisions. British Journal of Psychology, 83, 473-477.

Landman, J., Vandewater, A. A., Stewart, A. J., \& Malley, J. E. (1995). Missed opportunities: Psychological ramifications of counterfactual thought in midlife women. Journal of Adult Development, 2, 87-97.

Linder, D. E., Cooper, J., \& Jones, E. E. (1967). Decision freedom as a determinant of the role of incentive magnitude in attitude change. Journal of Personality and Social Psychology, 6, 245-254.

Lecci, L., Okun, M. A., \& Karoly, P. (1994). Life regrets and current goals as predictors of psychological adjustment. Journal of Personality and Social Psychology, 66, 731-741.

Markman, K. D., Gavanski, I., Sherman, S. J., \& McMullen, M. N. (1993). The mental simulation of better and worse possible worlds. Journal of Experimental Social Psychology, 29, 87-109.

Metha, A., Kinnier, R., \& McWhirter, E. M. (1989). Priorities and regrets of women. Psychology of Women Quarterly, 13, 167-174.

Morris, M. W., \& Moore, P. C. (2000). The lessons we (don't) learn: Counterfactual thinking and organizational accountability after a close call. Administrative Science Quarterly, 45, 737-765.

Nasco, S. A., \& Marsh, K. L. (1999). Gaining control through counterfactual thinking. Personality and Social Psychology Bulletin, 25, 556-568.

Netter, J., Kutner, M. H., Nachtsheim, C. J., \& Wasserman, W. (1996). Applied linear statistical models (4th ed.). New York: McGraw-Hill.

Oishi, S., \& Diener, E. (2001). Re-examining the general positivity model of subjective well-being: The discrepancy between specific and global domain satisfaction. Journal of Personality, 69, 641-666.

Roese, N. (2005). If only. New York: Broadway Books.

Roese, N. J. (1994). The functional basis of counterfactual thinking. Journal of Personality and Social Psychology, 66, 805-818.

Roese, N. J. (1997). Counterfactual thinking. Psychological Bulletin, 121, 133-148.

Roese, N. J., \& Olson, J. M. (1995). Outcome controllability and counterfactual thinking. Personality and Social Psychology Bulletin, $21,620-628$.

Schwarz, N. (1998). Accessible content and accessibility experiences: The interplay of declarative and experiential information in judgment. Personality and Social Psychology Review, 2, 87-99.

Schwartz, B. (2000). Self-determination: The tyranny of freedom. American Psychologist, 55, 79-88. 
Wicklund, R. A., \& Brehm, J. W. (1976). Perspectives on cognitive dissonance. Hillsdale, NJ: Lawrence Erlbaum.

Wrosch, C., \& Heckhausen, J. (2002). Perceived control of life regrets: Good for young and bad for old adults. Psychology and Aging, 17, 340-350.

Zeelenberg, M. (1999). The use of crying over spilled milk: A note on the rationality and functionality of regret. Philosophical Psychology, $12,325-340$.

Zeelenberg, M., Inman, J. J., \& Pieters, R. G. M. (2001). What do we do when decisions go awry: Behavioral consequences of experienced regret. In J. Baron, G. Loomes, \& E. Weber (Eds.), Conflict and tradeoffs in decision making (pp. 136-155). Cambridge, UK: Cambridge University Press.
Zeelenberg, M., \& Pieters, R. (1999). Comparing service delivery to what might have been: Behavioral responses to regret and disappointment. Journal of Service Research, 2, 86-97.

Zeelenberg, M., van der Pligt, J., \& Manstead, A. S. R. (1998). Undoing regret on Dutch television: Apologizing for interpersonal regrets involving actions or inactions. Personality and Social Psychology Bulletin, 24, 1113-1119.

Received June 4, 2004

Revision accepted January 1, 2005 